\title{
Mixing Suspensions in Tall Vessels with a Draught Tube
}

J. Brož, F. Rieger

A tall vessel with a telescopic draught tube is proposed for mixing suspensions. The paper presents the relations for calculating the agitator power consumption and the speed necessary to keep a particle in suspension.

Keywords: mixing equipment, draught tube, suspension.

\section{Introduction}

Large tall vessels with a draught tube (shown in Fig. 1) are used for mixing suspensions, especially when high homogeneity is desirable. A short shaft and a small ground area are advantages of this configuration.

\section{Modifications to a draught tube for particle suspension}

The main disadvantage of this arrangement is that particle suspension is difficult after mixing has been interrupted. As shown in Fig. 2, in the case of small particles the speed for initiating particle suspension $n_{\mathrm{p}}$ is significantly greater than the speed necessary to keep a particle in suspension $n_{\mathrm{k}}$.

Operation at high speed requires high power consumption. To overcome this difficulty, the telescopic withdrawable

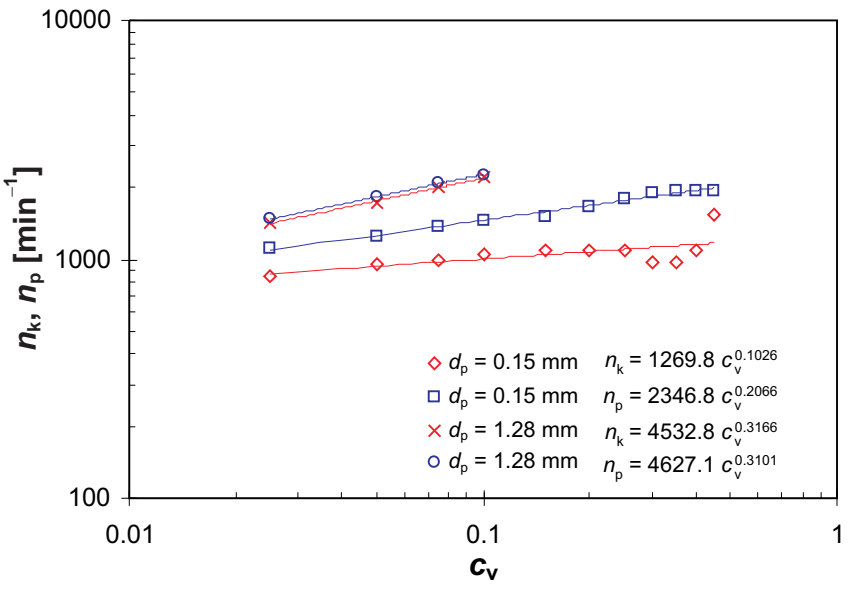

Fig. 2: Comparison of impeller speed $n_{\mathrm{k}, \mathrm{p}}$ for particle diameters $d_{\mathrm{p}}=1.28 ; 0.15 \mathrm{~mm}$

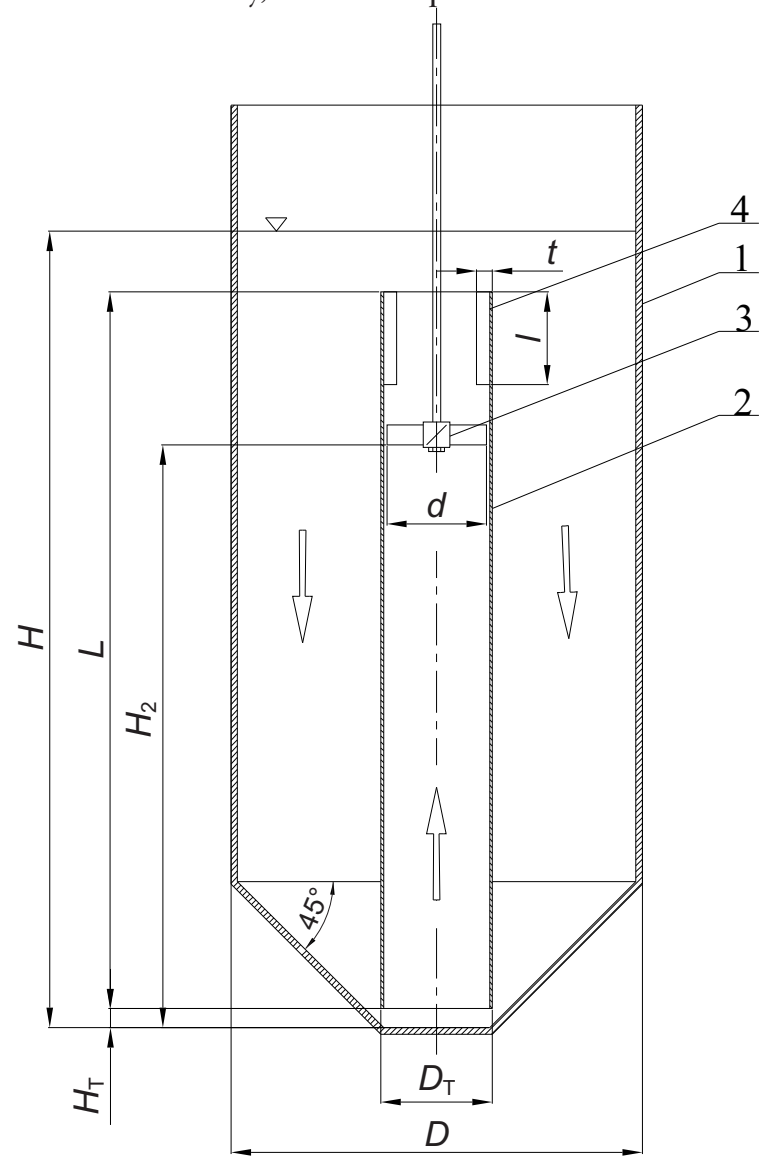

1 vessel

2 draught tube

3 impeller

4 baffles
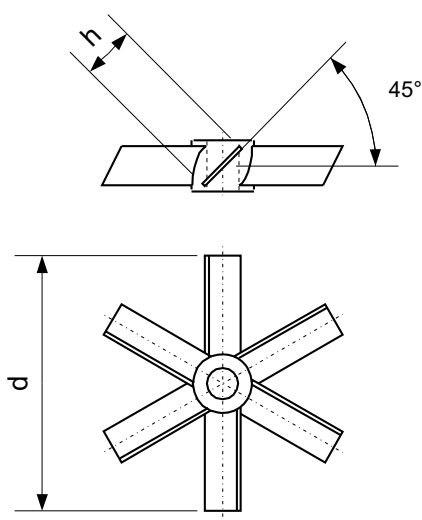

Pitched six-blade turbine

CVS $691020 \mathrm{~h} / \mathrm{d}=0.2$

Fig. 1: Mixing vessel with a draught tube 


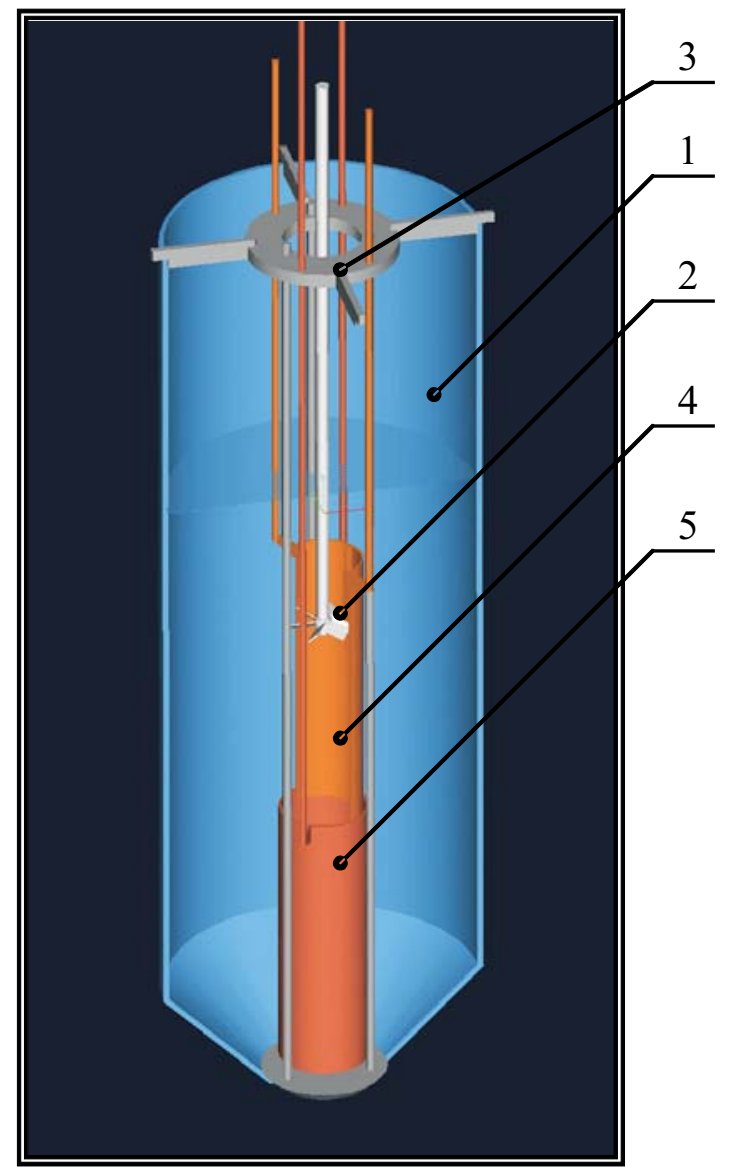

a) operating position

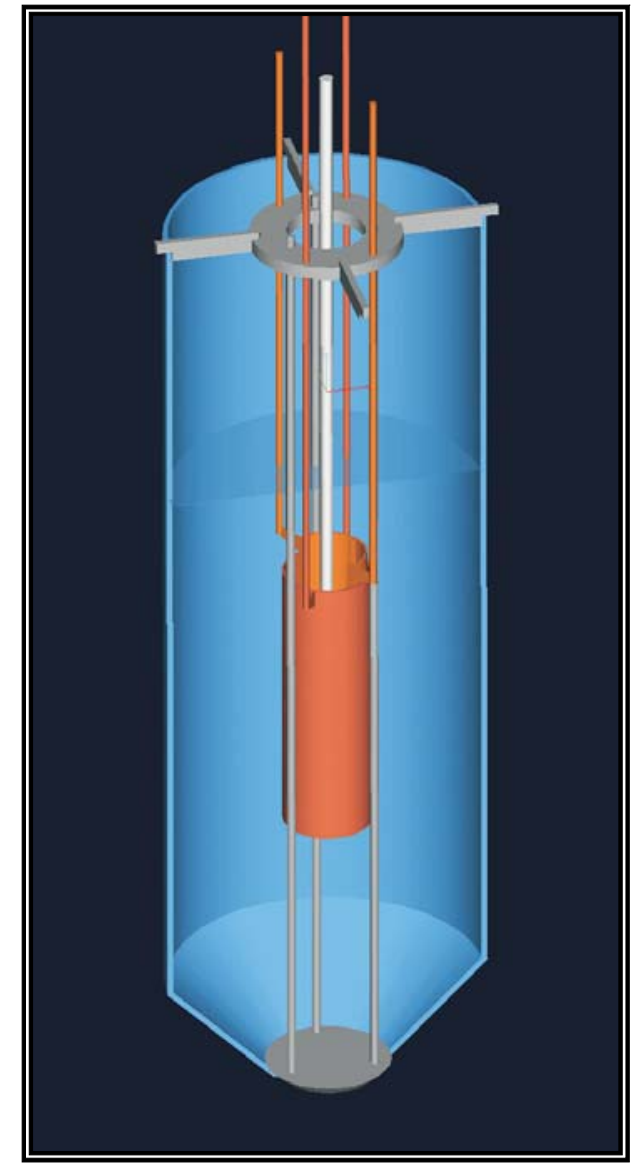

b) upper position

Fig. 3: Vessel with telescopic draught tube

draught tube shown in Fig. 3 has been proposed as a utility model [1].

For settled particle suspension, the draught tube is withdrawn to the upper position with a small gap between the sediment and the draught tube - Fig. 4a. The high liquid velocity in the gap causes particle suspension - Fig. 4b. Then the draught tube can gradually be lowered as the particles are suspended and the bed of settled particles decreases.

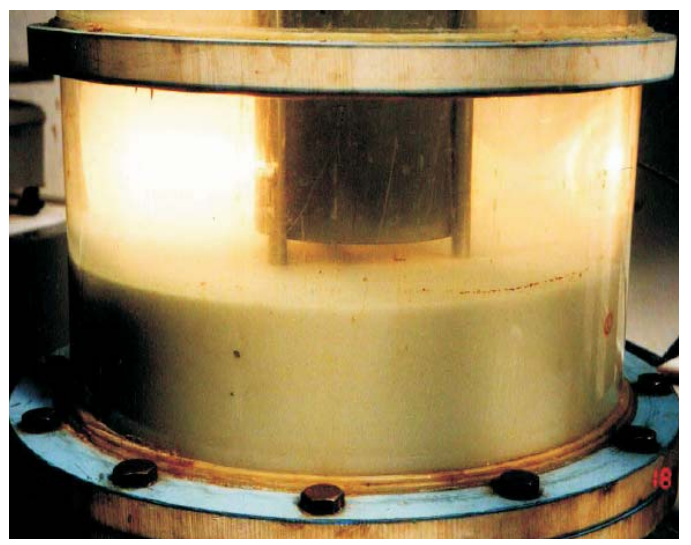

a)

\section{Experimental}

We need to know the power consumption and the critical agitator speed in order to design mixing equipment.

Measurements were carried out on the model mixing equipment shown in Fig. 5, with the dimensions presented in Table 1. Water suspensions of five fractions of glass balotine with mean diameters from 0.15 to $1.28 \mathrm{~mm}$ with volumetric content of particles $c_{\mathrm{v}}$ in the range from 0.025 to 0.45 were

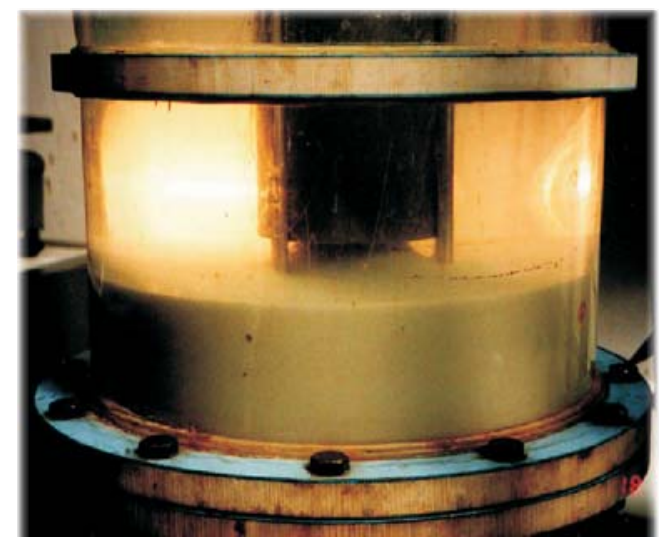

b)

Fig. 4: Draught tube above the sediment layer 
Table 1

\begin{tabular}{|c|c|c|c|c|c|c|c|c|c|c|}
\hline $\begin{array}{c}D \\
{[\mathrm{~mm}]}\end{array}$ & $\begin{array}{c}D_{\mathrm{T}} \\
{[\mathrm{mm}]}\end{array}$ & $\begin{array}{c}D_{1} \\
{[\mathrm{~mm}]}\end{array}$ & $\begin{array}{c}D_{\mathrm{M}} \\
{[\mathrm{mm}]}\end{array}$ & $\begin{array}{c}d \\
{[\mathrm{~mm}]}\end{array}$ & $\begin{array}{c}H \\
{[\mathrm{~mm}]}\end{array}$ & $\begin{array}{c}H_{\mathrm{T}} \\
{[\mathrm{mm}]}\end{array}$ & $\begin{array}{c}H_{2} \\
{[\mathrm{~mm}]}\end{array}$ & $\begin{array}{c}t \\
{[\mathrm{~mm}]}\end{array}$ & $\begin{array}{c}L \\
{[\mathrm{~mm}]}\end{array}$ & $\begin{array}{c}l \\
{[\mathrm{~mm}]}\end{array}$ \\
\hline 300 & 72 & 120 & 81 & 65 & 600 & 14 & 444 & 8 & 540 & 54 \\
\hline
\end{tabular}

used in the measurements. The power consumption was measured by a tensometric pick-up with a GMV amplifier

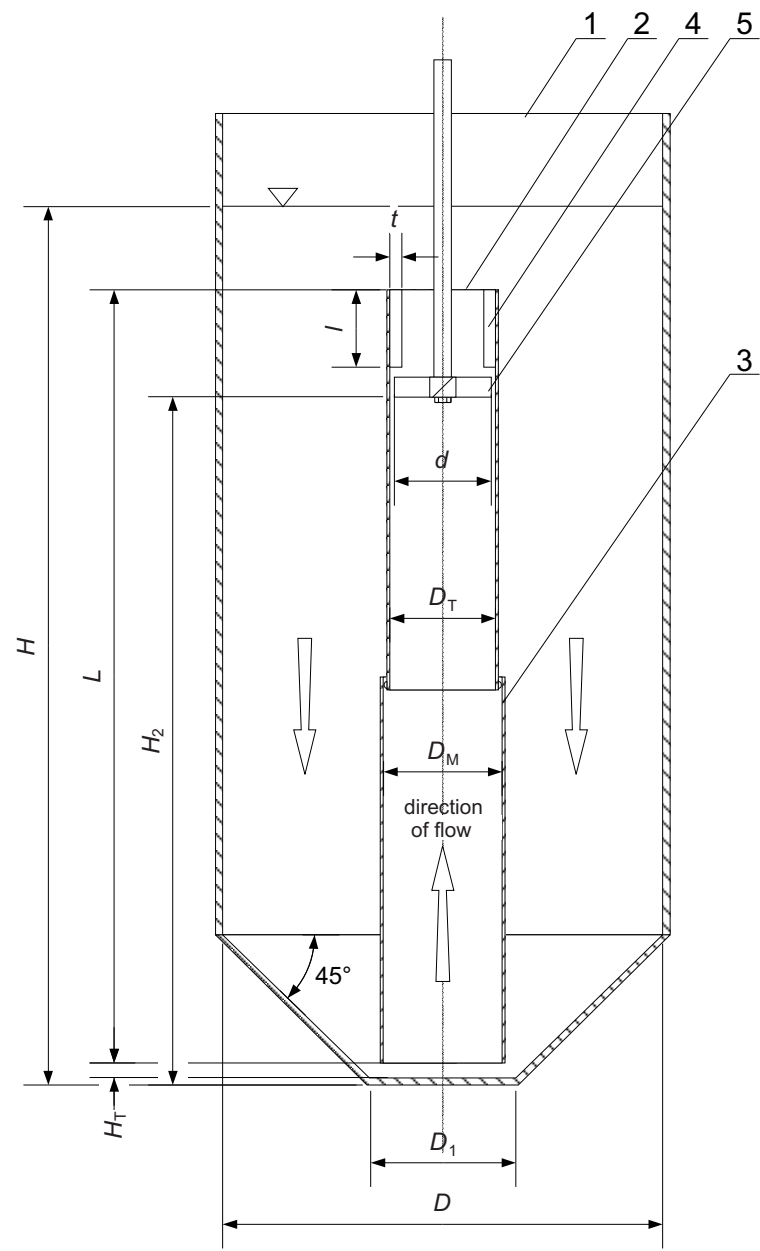

Fig. 5: Vessel with telescopic draught tube

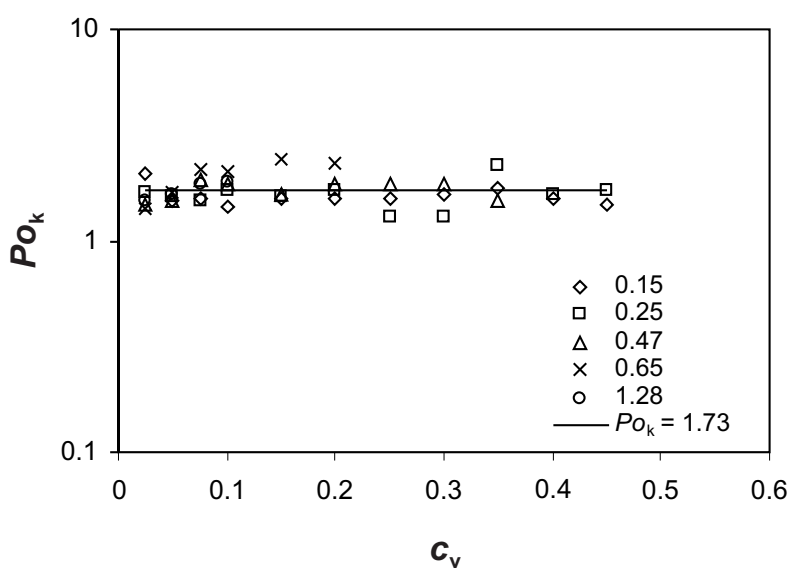

a) made by Lorenz Messtechnik at the agitator speed necessary to initiate $n_{\mathrm{p}}$ and maintain $n_{\mathrm{k}}$ particle suspension. The critical speed of the agitator was determined visually and measured photoelectrically.

\section{Experimental results}

The results of the power consumption measurements were processed to the form of power number $P o$ dependence on volumetric content $c_{\mathrm{v}}$ for various particle diameters shown in Fig. 6.

This figure shows that the power number is independent of particle content and size. The power number at the speed necessary to initiate particle suspension $P_{0}$ does not differ significantly from the power number at the speed necessary to keep a particle in suspension $P_{0}$, and its mean value is $P o=1.63 \pm 0.07$.

Measurements of the critical agitator speed necessary to keep a particle in suspension $n_{\mathrm{k}}$ have been presented in [2] The results were processed in the form of a dimensionless equation

$$
\mathrm{Fr}^{\prime}=A\left(\frac{d_{\mathrm{p}}}{D}\right)^{a}
$$

from which the critical agitator speed can be calculated. The coefficients in $a$ and $A$ depend on particle content and can be determined from the following relations

$$
\begin{aligned}
& a=0.47+2.26 \cdot c_{\mathrm{v}} \\
& A=40.07 \exp \left(17.62 \cdot c_{\mathrm{v}}\right)
\end{aligned}
$$

\section{List of symbols}

$\begin{array}{ll}c_{\mathrm{v}} & \text { mean volumetric concentration of particles } \\ d & \text { agitator diameter } \\ d_{\mathrm{p}} & \text { particle diameter }\end{array}$

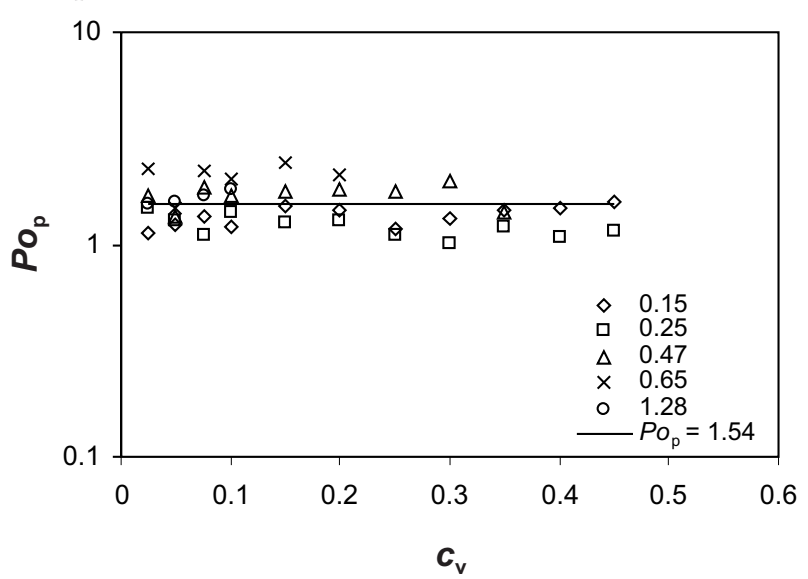

b)

Fig. 6: Power number $P o$ dependence on the mean particle volumetric content $c_{\mathrm{v}}$ : a) $\left.P o_{\mathrm{k}}=1.73 \pm 0.08, \mathrm{~b}\right) P o_{\mathrm{p}}=1.54 \pm 0.11$ 
D vessel diameter

$\mathrm{Fr}^{\prime} \quad$ modified Froude number, $\mathrm{Fr}^{\prime}=\frac{n_{\mathrm{k}}^{2} d \rho}{g \Delta \rho}$

$n \quad$ agitator speed

$P \quad$ power

$P o \quad$ power number, $P o=P \rho_{\mathrm{s}}^{-1} n^{-3} d^{-5}$

$\rho \quad$ density of liquid

$\rho_{\mathrm{s}} \quad$ density of suspension

$\Delta \rho \quad$ solid-liquid density difference

\section{Acknowledgement}

This work was supported by research project of the Ministry of Education of the Czech Republic MSM6840770035.

\section{References}

[1] Utility model proposal PUV 2009-20921.

[2] Brož, J., Rieger, F.: Czasopismo Techniczne. Vol. 105 (M/2008), No. 6, p. 29-36.

Jiří Brož

Prof. Ing. František Rieger, DrSc.

phone: .+420224352548

e-mail: frantisek.rieger@fs.cvut.cz

Department of Process Engineering

Czech Technical University in Prague

Faculty of Mechanical Engineering

Technická 4

16607 Prague 6, Czech Republic 